\title{
On the Fireproof Measures of Unattended Substation in Power System

\author{
Shi Lei ${ }^{1}$, Feng Xiaoming ${ }^{1}$, Chen Yan ${ }^{1}$, Li Haoluan ${ }^{2}$ \\ ${ }^{1}$ Yingkou Power Supply Company of National Grid Liaoning Electric Power Co., Ltd \\ ${ }^{2}$ Electrical and Electronic Engineering Institute of North China Electric Power University
}

jkweiz@sina.com, dianlilhı@163.com

\section{Keywords: Fireproof; Substation; Measures}

\begin{abstract}
In recent years, unattended substation has been widely promoted in power system. Although advanced automation technology has provided technical assurance for the development of unattended substation, the achievement of "no one left" at substations under the current situation requires not only high automatic level, but relatively complete fireproof and security measures, or the adoption couldn't realize the target of decreasing personnel and increasing efficiency. Benxi Power Supply Bureau takes fully consideration of the fireproof and security needs in developing unattended substations and achieves a relatively satisfactory result in organizational and technical aspects.
\end{abstract}

\section{Introduction}

As one of the most important facilities for customers to get access to electricity, substation can not only provides customers with necessary protections for secure and convenient use of electricity, but play an important role for the operational security, economy and reliability of the whole power network. Since the promulgation of relevant laws in China, people's fire fighting awareness has been generally enhanced by various fire fighting propaganda and inspection and supervision activities, promoting the implementation of fire fighting measures in all fields. Fireproof in substations is an important part in civil engineering design, but also an important means to prevent the occurrence of fires and reduce losses caused by fires. The construction department in China has made detailed investigations on many accidents according to the construction types and development and spread features of the fire, and designed building design fireproof specification, and fireproof design of tall buildings after research and analysis, providing references for people to take specific fireproof measures in civil engineering design of substation. It can be summed up into four aspects according to the types of work: fireproof in substation, sprinkler fireproof system in substation, air conditioning fireproof system, smoke preventing and dispelling system, electric fire protection, fire alarm control system and so on.

The existing fireproof measures include: smoke and heat detectors will alarm when fire are detected, then the attendant will get the signal in dispatch center by network transmission so that he can notify relevant personnel to come and put out the fire with several hand-held or wheeled fire extinguishers. The problem lies in that the smoke and heat detectors only alarms when the temperature becomes enough high. When the detection happens, especially for those where smoke and heat detectors are all placed on the roof of the room, the fire has spread from the cabinet to outside and imposes a great threat to other equipments. The workers have missed the best time to fight fire. What's more, as unattended substations are usually established in distant areas, the fire has spread so wide that extinguishers can do little when rescue workers or firefighters come to the scene. In addition, water that firefighters usually use to extinguish fires can lead to more serious damage of electrical equipment than fire. Despite the emergency power switch function of current unattended substations, fires that can not be extinguished in time would spread to other cabinets immediately, causing the whole substation to stop running and bring immeasurable losses. 


\section{Organizational Measures}

\section{Standardize Management Modes of Unattended Substations}

(1) combine the monitoring center and operation team originally directed by dispatch center and substation respectively into a monitoring and operation center directed by substation, so as to concentrate the staff and strengthen routine patrol in the unattended substation.

(2) hire a security guard or retiree for each substation as both doorkeeper and alarm handler.

\section{Strengthen fireproof and security measures in unattended substation}

(1) organize the great youth group to establish a voluntary fire protection and public security team. Strengthen their learning on fire protection knowledge, enhance fireproof and security awareness and improve their ability of handling emergency.

(2) introduce fireproof and security work into daily substation professional management and establish regular inspection system for fire protection equipment and anti-theft devices to ensure the perfect running condition.

(3) carry out inspections at night to enhance deterrence of criminals before they occur.

\section{Technical measures}

\section{Rational Allocation of Firefighting Equipment}

(1) equip sufficient firefighting equipment according to the substation scale, including fireproof shelf, fireproof sandbox, fire hydrant, fire buckets and fire extinguishers, etc..

(2) according to the requirements of typical fire fighting code of electricity equipment, substations should be equipped with dry carbon dioxide and carbon tetrachloride 1211. Fire extinguishers should be no foam type and be placed reasonably according to the fire protection and anti-theft measures of unattended substation for easy access.

\section{Application of Modern fireproof and anti-theft technologies}

(1) According to the requirements of unattended substation acceptance outline, substation should be equipped with fire alarm system to detect fire in the early stage. In this system, smoke detection is installed in each area to detect faint smoke accurately and reliably and send out signals to inform security personnel. What's more important, the device is able to control the signal system remotely while alarming, acquiring sounds or flashes of fire alarm and reminding the attendant in the monitoring center of the fire in time.

(2) Install remote inspection and warning equipment in unattended substations to ensure safety of the equipment and substation in distant areas. Except for image surveillance function, this system also own infrared alarm and substation lightening control function. Installed on the courtyard walls of substations, infrared alarm detector will alarm once someone enters and make a strong siren sound. Cameras with cruise function will be automatically aligned to the target and record the picture. After receiving the alarm, the monitoring center can shout over microphones to repel the intruders while watching the video. Cameras with cruise function can also be automatically aligned with the alarm area to check on the situation of fire.

Equip portable infrared temperature detectors for inspection personnel to detect the heating condition of equipment operation and lead connector, in case that the overheated equipment or lead cause fire. The detector needs no contact with energized equipment, but be able to align with the detecting points and measure the temperature of detection point accurately within 15 meters. 


\section{Implementation Effect}

Through the implementation of these measures, fireproof and anti-theft work in unattended substations have achieved good results. A substation in the southern city was once caught in fire due to overheated power line, and the smoke detector in the above succeeded in alarm accurately and timely so that the operational personage cut off the power of equipment in time and thus avoided the occurrence of fire accidents. In another comprehensive automation substation of the same bureau, there was once an outsider trying to climb over the wall, infrared alarm sent out alarm sound timely, and the intruder then fled. In a word, in order achieve fully withdrawal in substation, it is necessary to complete the fire protection and anti-theft measures.

\section{Conclusion}

The improving measures of the above proposed current situation and problems of substation can be summed up into 5 points:

(1) The construction should be designed reasonably and electricity equipment should be placed properly.

(2) Adopt advanced fire alarm systems like automatic smoke alarm system. It is better for unattended substations based in urban districts to install fire detection devices that can communicate with relatively units remotely. For those unattended substations in places of great importance, automatic fire extinguishing devices can be installed.

(3) Promote the application of newly developed fireproof materials with heat-resisting, :high temperature resisting and anti-burning features.

(4) apply professional fire-fighting equipment and hand-held or wheeled chemical fire extinguishers with materials like dry 1211 recommended by the code with good performance over oil fires. Such extinguishers can be stored for a long period, needs less inspection and maintenance work, which helps reduce the initial investment and are more convenient to use and able to extinguish fires in the early stage even before the arrival of professional fire fighters, which means they needs no professional team.

(5) Fire rating can be elevated properly, if possible, to improve and optimize the structure and achieve a scientific fireproof system.

In summary, only by consciously following the relevant technical regulations of fire protection and adopting appropriate technical measures to respect the seriousness of fire regulations can the occurrence of fire accidents be reduced or minimized. Ensure that each construction project is equipped with complete devices and functions. To take prevention as the main cause and have fire nipped in the bud is the duty and responsibility of each electricity designer.

\section{References}

[1] Hu Shan, Gu Qiwei. The Intelligent Long-distance Image Monitoring System of Unattended Substation [J]. Computer Engineering, 2003, 29(2): 218220.

[2] Jiang Wei, Wang Zhiqiang, Wu Liwen. The Application of Long-distance Image Monitoring System to Unattended Substation [J]. Power System, 2006, 7(4): 6062.

[3] Wang Lijuan, Zhang Haitao, Wu Xianghui. Integration of Networking of Fire Controlling and Security and Protection System in a School [J]. Low Voltage Apparatus, 2008, (4): 43 45, 50.

[4] Su Zhili, Chen Hebei. Security Prevention Monitoring System Based on Three-tier Structure [J]. Journal of Wuhan University of Technology(Information \& Management Engineering, 2001, 23(3): 2224. 
[5] Yuan Rongxiang, Tu Xiaoping On the Function and Networking of Long-Distance Image Monitoring System of Transformer Substation [J]. Proceedings of the CSU-EPSA, 2003, 15(5): 51 53, 82.

[6] Gao Huisheng, Li Ran, Zhao Zhenbing. Image Monitoring System and SCADA System [J]. Automation of Electric Power Systems Interconnection Practice. 2005, 29(6): 9397.

[7] Du Mingfang, Su Wei, Li Xianmin. Burglar Alarm System Integration of Ethernet Based on UDP Agreement [C] //Paper Collection 2 of 2007 China Instrument and Measurement Control Technology Exchange Meeting. Chengdu: [s. n.], 2007: 929932.

[8] Yang Yan. Long-distance Monitoring System of Power Substation [J]. China Public: Market, 2007(10): 103104. 